\title{
The ketosis-prone diabetes diagnosis dilemma-a case report
}

\author{
Camila Viecceli, Sheila Piccoli Garcia*, Thizá Massaia Londero, Ana Marina da Silva Moreira, luri Martin Goemann, \\ Gustavo da Fonseca Cipriani, Themis Zelmanovitz
}

From 20th Brazilian Diabetes Society Congress

Porto Alegre, Brazil. 11-18 November 2015

\section{Background}

Ketosis-prone diabetes (KPD) comprises diabetic ketoacidosis (DKA) without phenotypic characteristics of type 1 diabetes mellitus (T1D).

\section{Objective}

Discussion of KPD diagnosis through a case presentation.

\section{Materials and methods}

Clinical report and literature review.

\section{Results}

A 16-year-old African American male was brought to emergency with abdominal pain, vomiting, lack of appetite and loss of $13 \mathrm{~kg}$ (regular weight $152 \mathrm{Kg}$, BMI $42.5 \mathrm{~kg} / \mathrm{m}^{2}$ ). Evaluation detected dehydration, blood glucose of $550 \mathrm{mg} / \mathrm{dL}$, acidosis and ketonemia. There was no previous diagnosis of diabetes. He received management for DKA, with fluid therapy and regular insulin via continuous intravenous infusion (around 100-140UI/ day) for 4 days. Subcutaneous insulin regimen with $\mathrm{NPH}$ and regular at meals was initiated after correction of acidosis. He kept capillary glycemia around 250mg/ $\mathrm{dL}$ despite increasing doses of insulin and exclusion of other pathologies. Detectable C-peptide (1.32; 0.78$5.19 \mathrm{ng} / \mathrm{mL}$ ), negative glutamic acid decarboxylase antibodies (anti-GAD), along with laboratory tests done a year ago showing fasting plasma glucose of $117 \mathrm{mg} / \mathrm{dL}$ and glycated hemoglobin (A1c) of 6.2\%, justified starting metformin $850 \mathrm{mg} /$ day. Patient evolved with marked improvement of glycemic control and was discharged. He returned at the diabetes clinic after 1 month, bringing his self-monitoring showing capillary blood glucose between $60-130 \mathrm{mg} / \mathrm{dL}$ and $\mathrm{A} 1 \mathrm{c}$ of $9.3 \%$. Insulin was gradually reduced and metformin increased to maximum dose, leading to KPD hypothesis. Patient is currently receiving outpatient treatment and waiting result of HLA assessment.

\section{Discussion}

KPD presents with classical symptoms of DKA, but majority of patients are overweight/obese and middleaged Afro-American males. Incidence is increasing in younger patients. KPD is classified into four $A \beta$ groups, based on the presence or absence of autoimmunity $(\mathrm{A}+$; A-) and pancreatic $\beta$-cell functional reserve $(\beta+; \beta-)$. Negative anti-GAD and high $C$-peptide level classify the patient described above as A- $\beta+$ subgroup, which is characterized by DKA findings with clinical features of type 2 diabetes. Forty percent of these patients achieve insulin independence and glycemic control with oral agents only. Insulin withdrawal can be longer than 10-14 weeks.

\section{Concluison}

KPD should be investigated in young obese patients presenting with DKA, since treatment and follow up differs from T1D. Reversible $\beta$-cell dysfunction and remission to near normoglycemia is possible.

Published: 11 November 2015

doi:10.1186/1758-5996-7-S1-A104

Cite this article as: Viecceli et al:: The ketosis-prone diabetes diagnosis

dilemma-a case report. Diabetology \& Metabolic Syndrome 2015 7(Suppl 1): A104.

\footnotetext{
* Correspondence: sheilagarcia01@yahoo.com
}

HCPA, Porto Alegre, Brazil 